\title{
Prevalence of Extended Spectrum Beta Lactamase Producing Escherichia coli and Pseudomonas aeruginosa Isolated from Clinical Samples
}

\author{
W. Braide1 ${ }^{1}$, L.C. Madu1, S.A. Adeleye1, M.C. Korie², C.I. \\ Akobondu ${ }^{1}$
}

\begin{abstract}
${ }^{1}$ Department of Microbiology, Federal University of Technology, P.M.B 1526, Owerri, Imo State, Nigeria ${ }^{2}$ Department of Science Laboratory Technology, Imo State Polytechnic Umuagwo-Ohaji, Imo State, Nigeria
\end{abstract}

\begin{abstract}
There has been an increasing attention globally over the rising treatment failures caused by Extended Spectrum Beta-Lactamase (ESBL) producing organisms when new generation antibiotics are used. This study was carried out to investigate the prevalence of ESBL producing Escherichia coli and Pseudomonas aeruginosa isolates from the Federal Medical Centre (FMC) Owerri, Imo State, Nigeria. Two hundred and fifty clinical isolates comprising, E. coli (136) and P. aeruginosa (114) was used for the study. Antimicrobial susceptibility testing of isolates was determined using the disc diffusion method. ESBL phenotypes were further determined by the double disc synergy test using Ceftazidime, Cefotaxime, Ceftriazone and Amoxicillin clavulanic acid. Out of the 250 isolates tested, 114 (45.6\%) were positive for ESBL production comprising 66(26.4\%) E. coli and 48(19.2\%) P. aeruginosa. The antimicrobial sensitivity testing showed that the highest resistance of $100 \%$ was recorded with Cephalexine while the least of $0 \%$ was recorded with the aminoglycosides and quinolones, giving a clear indication that the aminoglycosides and quinolnes could be recommended for the treatment of ESBL infections caused by these organisms. The result of the present study showed that there is apparently high prevalence of ESBL producing $E$. coli and $P$. aeruginosa in the Federal Medical Centre (FMC) Owerri, Imo State, Nigeria.
\end{abstract}

Keywords: Escherichia coli, ESBL, Prevalence, Antimicrobial susceptibility

\begin{abstract}
Introduction
Extended-Spectrum Beta-lactamases (ESBL) are $\beta$ lactamases capable of conferring bacterial resistance to the penicillin, and third generation cephalosporins, and aztreonam, but not the cephamycins or carbapenems (Paterson and Bonomo, 2005) and are usually encoded on plasmids which frequently carry genes encoding resistance to other classes of antibiotics. Extended Spectrum beta lactamases (ESBL) were first described in the 1980s and they have been detected in Klebsiella species, and later in Escherichia coli, Pseudomonas aeruginosa and Serratia marcescens and other gram-negative bacilli (Kiratisin et al., 2008; Nwosu et al., 2014; Yushau et al., 2010; Ullah et al., 2009). A good number of enteric gram-negative bacteria have been shown to posses naturally occurring chromosomally mediated genes that confer resistance on them to $\beta$-lactam antibiotics (Nwosu et al., 2014; Yushau et al., 2010; Ullah et al., 2009; Sabrina et al., 2010; Haque and
\end{abstract}

Salam, 2010; Bhusal et al., 2011; Sibhghatulla et al., 2015; Madja et al., 2013; Nasa et al., 2012; Sankars et al., 2012; Shakti et al., 2014; Rupinda et al., 2013). ESBL strains are inhibited by $\beta$-lactamase inhibitors such as clavulanic acid, sulbactam, and tazobactam (Bradford, 2001). ESBLs are an increasingly important cause of transferable multidrug resistance in gram-negative bacteria throughout the world. These bacteria have spread rapidly and have become a serious threat to human health worldwide. The gram-negative bacilli especially Pseudomonas species and members of the family enterobacteriaceae are common causes of infections of many parts of the body. They account for more than $50 \%$ of all isolates in nosocomial infections (Talaro and Talaro, 1996). Among the most prevalent bacteria pathogens capable of showing resistance to common antibiotics is Escherichia coli which is one of the most common causes of urinary tract infections and other opportunistic infections such as wound

This article is published under the terms of the Creative Commons Attribution License 4.0

Author(s) retain the copyright of this article. Publication rights with Alkhaer Publications.

Published at: http://www.ijsciences.com/pub/issue/2018-02/

DOI: 10.18483/ijSci.1556; Online ISSN: 2305-3925; Print ISSN: 2410-4477 
abscess which can have serious clinical implication (Iroha et al., 2009). Originally, ESBL enzymes were derived from the wide spread TEM and SHV $\beta$ lactamase family, however today, over 110 derivatives of TEM $\beta$-lactamase and more than 63 derivatives of SHV $\beta$-lactamases are known. ESBLs are undergoing continuous mutation, causing the development of new enzymes showing expanded substrate profile. At present, there are more than 300 different ESBL variants and these have been clustered into nine different structural and evolutionary families based on amino acid sequence.TEM (Temoniera) and Sulphhydril variable SHV were the major types. However, CTX-M (Cefotaxime-Munich) is more common in some countries (Paterson et al., 2003).The ESBL enzymes are most commonly produced by Klebsiella species and Escherichia coli, but may also occur in other gram-negative bacteria including Salmonella, Proteus, Citrobacter, Morganella, Serratia, and Shigella species. That ESBLs are encoded on plasmids and are therefore easily transmissible from one organism to another is a therapeutic challenge for physicians as resistance genes for other antimicrobials such as aminoglycosides, tetracycline, and trimethoprim/sulfamethoxazole are often present on the plasmid (Jones, 2001) thereby contributing further to the narrowing of choices of antibiotics.

This study reports on the prevalence and antimicrobial sensitivity pattern of ESBL producing isolates of E. coli and P. aeruginosa from specimens such as urine, wound swab and HVS. The antimicrobial susceptibility pattern of ESBL producing $E$. coli and $P$. aeruginosa isolates was also determined.

\section{Materials and Methods \\ Collection of Clinical Isolates}

Two hundred and fifty clinical bacterial isolates from the Microbiology Laboratory unit of the Federal Medical Centre (FMC), Owerri, Nigeria were used for the study. The isolates were obtained from the clinical specimen, urine, wound swab and HVS. All isolates were identified on the basis of colonial appearances, gram staining reactions and standard biochemical test (Cheesbrough, 2005)

\section{Antimicrobial Susceptibility Testing}

Antimicrobial susceptibility testing was carried out on all the isolates by the Kirby bauer disc diffusion method as recommended by the CLSI (2010). Sterile petri-dishes of Mueller Hinton agar were prepared according to manufacturer's specification. Colonies of an overnight culture were suspended in normal saline and the turbidity adjusted to 0.5 McFarland turbidity standards. A sterile cotton wool swab was inserted into each test tube containing the standardized inoculums suspension, rotated with firm pressure on the side wall of the test tube to remove excess fluid and used to inoculate the entire surface of the Mueller Hinton agar plate.

The antibiotics used in the testing include Ceftazidime $30 \mu \mathrm{g}$, Cefotaxime $30 \mu \mathrm{g}$, Ceftriazone

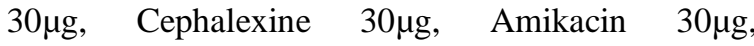
Gentamicin $30 \mu \mathrm{g}$, Tetracycline $30 \mu \mathrm{g}$, ofloxacin $5 \mu \mathrm{g}$, Amoxicilin clavulanic acid 30 $\mu$ g (oxoid, UK). All plates were incubated at $37{ }^{\circ} \mathrm{C}$ for $24 \mathrm{hrs}$ and the diameter of zones of inhibition was measured to the nearest millimetre using a transparent ruler.

\section{Detection of ESBL Production}

All suspected colonies were inoculated in peptone water at $37{ }^{\circ} \mathrm{C}$ for $6 \mathrm{hrs}$ and their turbidity adjusted to $0.5 \mathrm{McFarland}$ turbidity standards. Several plates of Mueller Hinton ager were prepared and $30 \mu \mathrm{g}$ disc of Ceftazime, Cefotaxime, and Ceftriazone, were placed $55 \mathrm{~mm}$ centre to centre from the amoxicillin clavolanic acid disc $(20: 10 \mu \mathrm{g})$. The Standardized inoculums were inoculated into Mueller Hinton agar plate and incubated at $37^{\circ} \mathrm{C}$ over night. Enhanced zones of inhibition between any of the beta -lactam discs and the centre disc were recorded as ESBL producers according to the (CLSI, 2010) criteria. Control strain used for the study was E. coli ATCC 25922.

\section{Results}

Antibacterial susceptibility testing by disc diffusion method showed that the highest resistance of $100 \%$ was recorded with cephalexin while the lowest of $0 \%$ resistance was observed with the quinolones and aminoglcosides (Table 1). Among the third generation cephalosporins tested, the highest resistance of $94.9 \%$ was observed with cefotaxime while ceftazidime had the lowest resistance rate of 3 . $5 \%$. 
Prevalence of Extended Spectrum Beta Lactamase Producing Escherichia coli and Pseudomonas aeruginosa Isolated from Clinical Samples

Table 1: Resistance pattern of $E$. coli and P. aeruginosa isolates

\begin{tabular}{|l|l|l|}
\hline $\begin{array}{l}\text { Antimicrobial agents } \\
(\mu \mathrm{g})\end{array}$ & $\begin{array}{l}\text { E. coli } \\
\text { Resistance }(\%)\end{array}$ & $\begin{array}{l}\text { P. aeruginosa } \\
\text { Resistance }(\%)\end{array}$ \\
\hline Ceftazidime (30) & $112(82.4)$ & $4(3.5)$ \\
Cefotaxime (30) & $129(94.9)$ & $103(90.4)$ \\
Ceftriazone (30) & $114(83.8)$ & $103(90.4)$ \\
Ofloxacin (5) & $0(0)$ & $114(100)$ \\
Perfloxacin (5) & $0(0)$ & $0(0)$ \\
Gentamicin (30) & $136(100)$ & $0(0)$ \\
Tetracycline (30) & $136(100)$ & $0(0)$ \\
Ciprofloxacine(5) & $0(0)$ & $0(0)$ \\
Amikacin (30) & $0(0)$ & $0(0)$ \\
\hline
\end{tabular}

Table 2: Distribution of ESBL producers from different specimen.

\begin{tabular}{|l|l|l|l|}
\hline Clinical Samples & E. coli & P. aeruginosa & Total \\
\hline Urine & $52(20.8 \%)$ & $17(6.8 \%)$ & $69(27.6 \%)$ \\
Wound swab & $0(0 \%)$ & $28(11.2 \%)$ & $28(11.2 \%)$ \\
HVS & $17(6.8 \%)$ & $0(0 \%)$ & $17(6.8 \%)$ \\
Total & $69(27.6 \%)$ & $45(18 \%)$ & $114(45.6 \%)$ \\
& & & \\
\hline
\end{tabular}

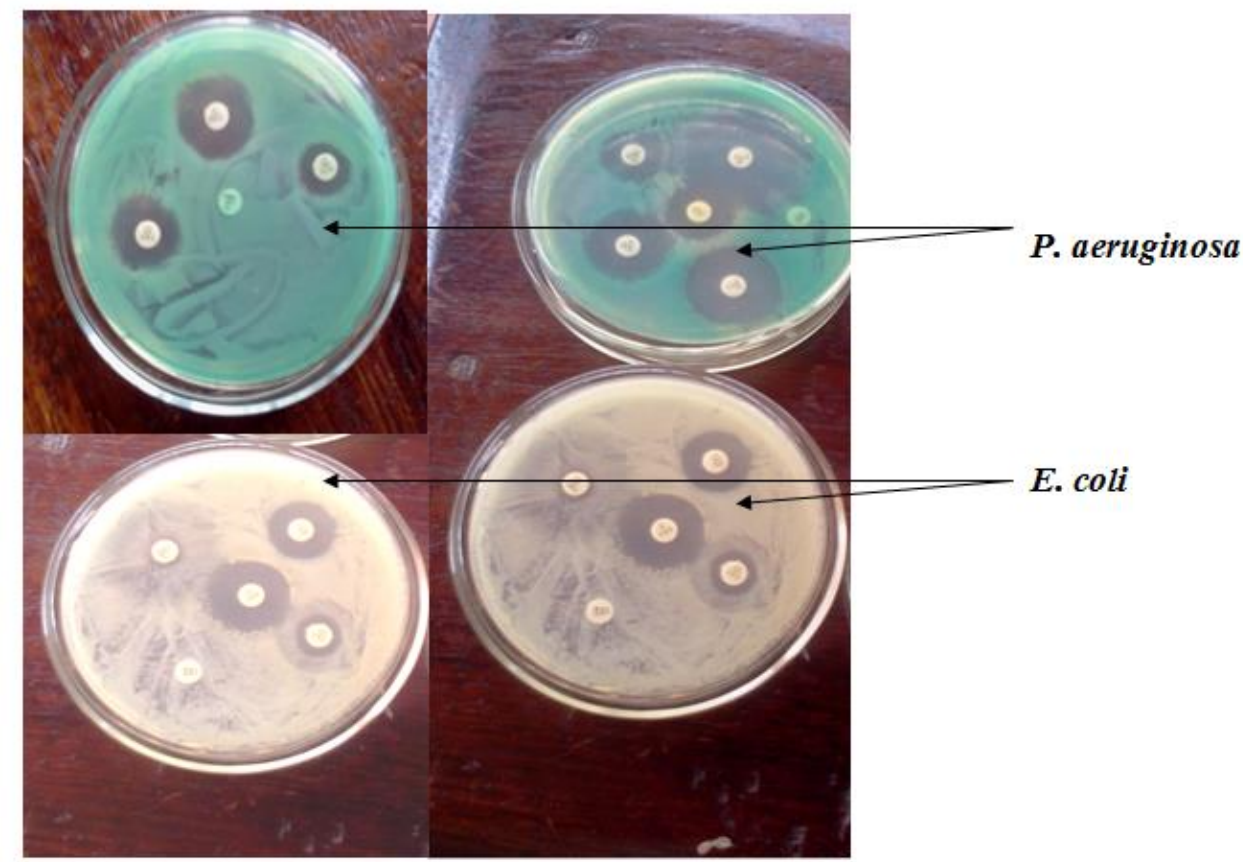

PLATE 1: $E$. coli and $P$. aeruginosa plates showing zones of inhibition using Kirby-Bauer method. 


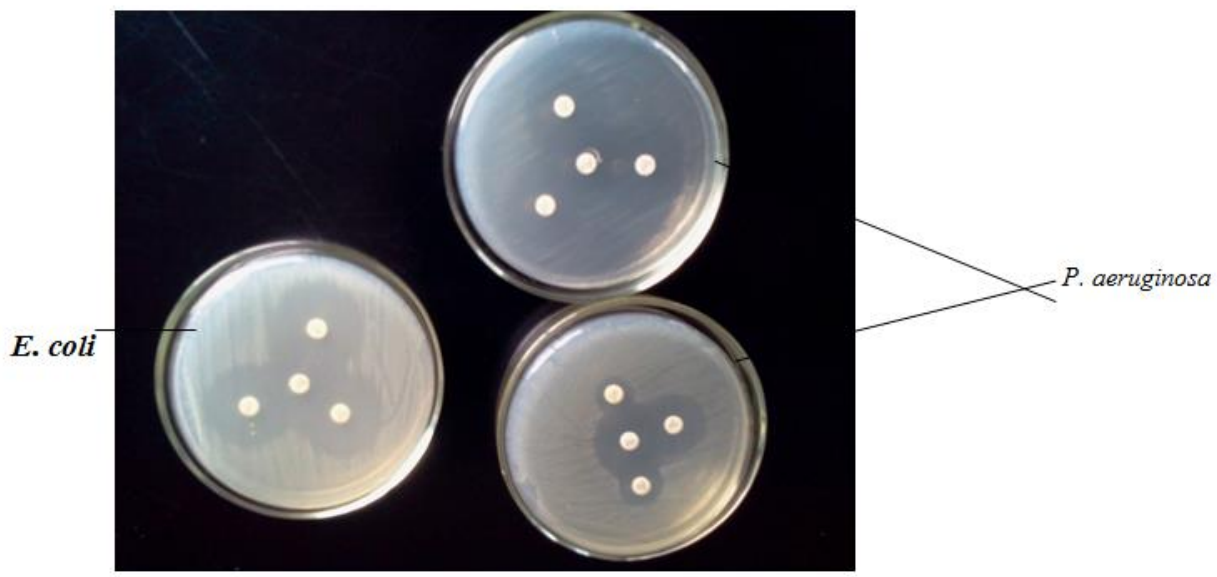

PLATE 2: Double Disk Synergy Test showing $E$. coli and $P$. aeruginosa plates with enhanced inhibition zones.

The result shows that out of the 250 clinical isolates (Escherichia coli and Pseudomonas aeruginosa) tested, $114(45.6 \%)$ were positive for ESBL production (Table 2) and Plate 1 shows plates of $E$. coli and $P$. aeruginosa plates with zones of inhibition. The susceptibility study shows that for both isolates, the highest resistance of $100 \%$ was recorded with cefalexine while the least of $0 \%$ was recorded with the quinolones ofloxacin and perfloxacin and aminoglycosides Amikacin and ciprofloxacin (Table 1) and Plate 2 which shows $E$. coli and $P$. aeruginosa with enhanced zones of inhibition.

\section{Discussion}

The present study has demonstrated the existence of ESBL producing $E$. coli and $P$. aeruginosa isolates here in the Federal Medical Centre (FMC) Owerri, Imo State, Nigeria. Out of the 250 isolates comprising E. coli (136) and $P$. aeruginosa (114) only, only $(45.6 \%)$ were confirmed positive for ESBL production as judged by the CLSI definition using the double disc synergy test. Out of the 114(45.6\%) ESBL positive isolates, 66(26.4\%) were E. coli and 48(19.2\%) were $P$. aeruginosa.

Among the third generation Cephaloporins recommended by CLSI used in the study, Cefotaxime showed the highest resistance rate of $94.9 \%$ and 90.4\% while Ceftazidime has the least resistance rate of $82.4 \%$ and $3.5 \%$ for $E$. coli and P. aeruginosa respectively. The result showed that $E$. coli was resistant to all the third generation antibiotics with $82.4 \%, 96.9 \%$ and $83.8 \%$ respectively. This is in accordance with the $85 \%, 84 \%$ and $75 \%$ recorded in the works of Sasirekha et al. (2010).
A study carried out in a tertiary hospital in South Indiana recorded a multidrug resistance case in which Cefotaxine was among the drugs with the highest resistance rate of $100 \%$ (Padmini et al., 2008). No resistance was recorded with the fluoroquinolones Ciproflaxin, ofloxacin and Perfloxacin. The aminoglycosides Amikacin and Perfloxacin also showed a $0 \%$ resistance. Some studies have also shown that fluoroquinolones and aminoglycosides have antimicrobial activity against ESBL organisms than other non-beta lactam drugs (Jean et al., 2002; Quale et al., 2002). It is interesting to note that the high susceptibility of the fluoroquinolones and the aminoglycosides among other non-beta lactam drugs gave a good indication that they could be a drug of choice in treating infections caused by ESBL producing organisms' particularly $P$. aeruginosa and E. coli in the environment.

Consequently, the data highlights a high prevalence of ESBL in Owerri, Nigeria. The 45.6\% ESBL recorded in this study is in accordance with the $52.4 \%$ high prevalence of ESBL recorded between 2003 - 2007 in Southern and Eastern Nigeria (Aibinu et al., 2003). It is however higher than the $7.5 \%$ of ESBL producers recorded in Ogun State (Ruth et al., 2011) and the $16 \%$ ESBL producers reported in South Eastern Nigeria (Akujobi and Ewuru, 2010). In conclusion, this study has revealed the presence of ESBL producing E. coli and P. aeruginosa in Imo, State Nigeria. The study recommends collaboration between physicians and laboratory scientist before administering any cephalosporin to patients. In addition, molecular typing is sine qua non in determining type of ESBL presents in each isolate which is essential for a reliable epidemiology of antimicrobial resistance.

\section{References}

1. Aibinu, I.E., Ohaghulam, V.C., Adenipekun, E.A., Ogunshola, F.A., Odugbemu, T.O and Mee, B.J. (2003). Extended Spectrum ß-lactamase Enzymes in clinical isolates of 
Enterobacteriaceae species from Lagos, Nigeria. Journal of Clincal Microbiology. 41 (5) 2197-2200.

2. Akujobi, C.N and Ewuru, C.P. (2010). Detection of extended spectrum beta-lactamases in gram negative bacilli clinical specimens in a teaching hospital in south eastern Nigeria. Nigerian Medical Journal. 51:141-6.

3. Bhusal, Y., Mihu, C.N., Tarrand, J.J and Rolston, K.V. (2011). Incidence of fluoroquinolone-resiatant and extended spectrum beta-lactamase-producing Escherichia coli at a comprehensive cancer center in the United State. Chemotherapy, 57 (4):335-338.

4. Bradford, P.A. (2001). Extended Spectrum B-lactamases in the $21^{\text {st }}$ century; characterization, epidemiology and detection of this important resistance threat. Clinical Microbiology. Rev. 14:933-951.

5. Cheesbrough, M. (2005). District Laboratory_Practice in Tropical Countries. $2^{\text {nd }}$ Edition.

6. Cambridge University Press. U.K. pp 465-478.

7. Clinical and Laboratory Standards Institute, CLSI (2009). Performance Standards for Antimicrobial Susceptibility Testing, 19th informational supplement, M100-S19. Wayne, PA: Clinical and Laboratory Standards Institute.

8. Haque, R and Salam, M. (2010). Detection of ESBL producing nosocomial gram negative bacteria from a tertiary care hospital in Bangladesh. Pakistan Journal of Medical Sciences, 26(4): 887-891.

9. Iroha, I.R., Adikwu, M.C., Esimone, C.O., Amadi, E.S and Aibinu, I. (2009). Extended Spectrum Beta lactamase (ESBL) in Escherichia coli isolates from a tertiary hospital in Enugu State. Pakistan Journal of Medical Science; 25(2):279-288.

10. Jean, S., Teng, L., Hauch, P., and HosLuh, K. (2002). Antimicrobial susceptibility among clinical isolates of extended spectrum cephalosporin-resistant gram-negative in a Taiwanese University. J. Antimicrob. Chemother. 49:6979.

11. Jones, R.N. (2001). Resistance pattern among nosocomial pathogens. Trends over the past few years. Chest., 119(2): 397-404.

12. Kiratisin, P., Apisarnthanarak, A., Laesripa, $C$ and Saifon, $P$. (2008). Molecular Characterization and Epidemiology of Extended-Spectrum Beta-Lactamase-Producing Escherichia coli and Klebsiella pneumoniae Isolates Causing Health CareAssociated Infection in Thailand, Where the CTX-M Family is Endemic. Antimicrob. Agents Chemother., 52: 2818-2824.

13. Madja, Q., Najma, A and Summyia, B. (2013). Evaluation of extended spectrum beta-lactamase mediated resistance in Escherichia coli in a tertiary care hospital. Biomedica, 29: 7881.

14. Nasa, P., Juneja, D., Singh, O., Dang, R and Singh, A. (2012). An observational study on bloodstream extended spectrumbeta-lactamase infection in critical centre unit: incidence, risk factorsand its impact on outcome. European Journal. Intern. Med., 23(2): 192-195.

15. Nwosu, I.L., Amadi, E.S., Nwanyanwu, C.E., Chikwendu, I.C and Madu, C.L. (2014). The prevalence of extended spectrum beta-lactamase (ESBLs) among Escherichia coli and Klebsiella species urinary isolates from Abia State University Teaching Hospital (ABSUTH) Aba, Abia State. International Journal of Microbiology and Mycology, 2(3):20-28.

16. Padmini, S., Baby, R., Appalla, B and Mani, K.R. (2008). Detection of Enterobacteriaceae producing CTX-M extended spectrum $\beta$ - lactamase from a tertiary care hospital in India. Indian Journal of Medical Microbiology. 26(2), 163-166.

17. Paterson, D. L., Hujer, K. M., Hujer, A.M., Yeiser, B., Bonomo, M.D., Rice, L.B and Bonomo, R.A. (2003). The International Klebsiella Study Group Extended-Spectrum Beta-Lactamases in Klebsiella pneumoniae Bloodstream Isolates from Seven Countries: Dominance and Widespread Prevalence of SHVand CTX-M- Type Beta-Lactamases. Antimicrob. Agents Chemother.. 47: 3554-3560.

18. Paterson, D.L and Bonomo, R.A. (2005). Extended-spectrum $\beta$-lactamases: A clinical update. Microbiol. Clin. 18:657-86.

19. Quale, J.M., Landman, D and Bradford, P.A. (2002). Molecular epidemiology of a citywide out breaks of extended spectrum bet-lactamase producing Klebsiella pneumoniae infection. Clin. Infect. Dis., 35:834-841.

20. Rupinder, B., Geeta, W and Shikha, J. (2013). Prevalence of extended spectrum beta-lactamases in multidrug resistant strains of Gram negative Bacilli. Journal Acad. Indus. Res., 1(9): 558-560.

21. Ruth, A.A., Damian, C.O., Romanus, I.I and Charles, O.E. (2011). Antimicrobial resistant status and prevalence rates of extended spectrum beta-lactamase producers isolated from a mixed human population. Bosnian Journal Basic Medical Science, 11(2): 91-96.

22. Sabrina, J.M., Said, A., Mabula, K., Eliguis, F.L and Samrel, Y.M. (2010). Antimicrobial resistance among producers and non producers of extended beta-lactamases in urinary isolates at a tertiary hospital in Tanzania. BMC Research Notes, 3:348.

23. Sankar, S., Narayanan, H., Kuppanan, $\mathrm{S}$ and Nandagopal, B. (2012). Frequency of extended spectrum beta-lactamase (ESBL) producing Gram negative bacilli in a 200-bed multispecialty hospitalin Vallore district, Tamil, Nadu, India. Infection, 40(4): 425-429.

24. Sasirekha, B., Manasa, R., Ramya, P and Sneha, R. (2010). Frequency and antimicrobial sensitivity pattern of extended spectrum $\beta$-lactamases producing Escherichia coli and Klebsiella pneumoniae isolated in a tertiary care hospital Al Ameen. Journal of Medical Sciences, 3(4):265-271.

25. Shakti, R., Debasmita, D., Mahesh, C., Sahu, R and Padhy, N. (2014). Surveillance of ESBL producing multidrug resistant Escherichia coli in a teaching hospital in India. Asian Pacific Journal of Tropical Diseases, 4(2): 140-149.

26. Sibhghatullas, S., Jamale, F., Shazi, S., Syed, M.D.R and Mohammed, A.K. (2015). Antibiotic resistance and extended spectrum beta-lactamases: Types, Epidemiology and Treatment. Saudi Journal of Biological Sciences, 22(1): 90101.

27. Talaro, K., and Talaro, A. (1996). Foundations in Microbiology. $2^{\text {nd }}$ edition. WCB/McGraw-Hill USA. pp609629.

28. Ullah, F., Malik, S.A and Ahmed, J. (2009). Antimicrobial susceptibility pattern and ESBL prevalence in Klebsiella pneumoniae from urinary tract infections in the North West of Pakistan. African Journal of Microbiology, 3(11): 670-680.

29. Yushau, M. M., Kumurya, A. S and Suleiman, L. (2010). Prevalence of extended $\beta$-lactamases among Enterobacteriaceae in Murtala Mohammed specialty hospital, Kano. Journal of Pure and Applied Sciences, 3(1): 169-172. 